\title{
Film Image Transfer System (FITS): An Efficient Method for Proper Positioning of Orthodontic Mini-implants
}

\author{
Taek-Su Go', Seong-Hun Kim², Gerald Nelson ${ }^{3}$
}

1. Department of Oral and Maxillofacial Surgery, Uijeonbu St. Mary's Hospital, The Catholic University of Korea, Uijeongbu, Korea

2. Department of Orthodontics, College of Dentistry, Kyung Hee University Medical Center, Seoul, Korea

3. Division of Orthodontics, The University of California, San Francisco, USA

\section{Corresponding Author}

Seong-Hun Kim, DMD, MSD, PhD

Department of Orthodontics, College of Dentistry, Kyung Hee University, \#1 Hoegi-dong, Dongdaemungu, Seoul 130-701, Korea

TEL : +82-2-958-9392 FAX : +82-2-966-7160 E-mail : bravortho@hanmail.net

Received for publication Apr 25, 2011; Returned after revision May 23, 2011;

Accepted for publication Jun 7, 2011

\section{- Abstract}

Purpose: To describe the newly developed Film image transfer system (FITS) for proper positioning of the orthodontic mini-implant in the narrow interdental space and considerations for better application.

Materials and Methods: A patient who was planning to have orthodontic mini-implant treatment on the posterior maxilla was recruited to assess the feasibility of FITS. Dental radiographic film and bite record was taken. And then the film image was transferred on the photographic emulsion coated model using transfer light through film projector (enlarger). After exposing the photo emulsion coating on the model, the image was developed with a working solution for a paper developer and fixed. The surgical guide for the miniimplant was fabricated from the transported FITS data.

Results: The completed surgical guide was easily placed intraorally, and allowed a simple and rapid placement of the mini-implant. The site of the implant placement was accurate as planned position.

Conclusion: In the reported case, The FITS technique represents an effort to minimize risk to the patient and produce consistently good results based upon accurate information about the anatomy of the implant site.

- Key word : Surgiguide, Periapical film, Mini-implant, Film Image transfer system, Osseointegration, Hyperrealism

- J Kor Dent Sci. 2011; 4(1): 20 - 25

(a) This is an open access article distributed under the terms of the Creative Commons Attribution Non-Commercial License (http:// creativecommons.org/licenses/by-nc/3.0) which permits unrestricted non-commercial use, distribution, and reproduction in any medium, provided the original work is properly cited. 


\section{Introduction}

A surgical template was used as a guide to locate the implant fixture vertically in oral and maxillofacial surgery ${ }^{1-3}$. The conventional surgical template on the dental cast provides guidance in relation to superficial alveolar and dental anatomy, but can not ensure safe implant placement in relation to the root structure ${ }^{1)}$. In some cases roots are not present (e.g. multiple missing teeth), and consideration of root damage is not relevant.

On the contrary, the typical position for the orthodontic mini-implant is in alveolar bone containing healthy dental roots $^{4-8)}$. An orthodontic mini-implant installed without a correct surgical template, has the risk of root injury, penetration of the maxillary sinus, or poor stability ${ }^{9,10}$. If the surgical template is manufactured just on the study model, the risk of root damage while navigating the narrow space between roots is very high. So, we need an accurate surgical template or guide to reduce operation time and to locate both the point of insertion and the interior location of the screw adjacent to roots and sinuses.

Since periapical radiographs show stable enlargement ratio and finds the narrowest point precisely, many clinicians are using them when installing mini-implants ${ }^{1,9-12)}$. Surgical templates based on superficial anatomy only have been reported by some authors ${ }^{1,9}$. On the contrary, some authors suggested an adjustable surgical guide or 3-D surgical guide for accurate positioning of a miniscrew and avoiding nearby dental roots using simple periapical radiographs ${ }^{10-12)}$. However, this approach is still an estimate of the drill site, and more certainty would require successive radiographs until the mini-implant is safely placed and correctly positioned. If the periapical film image, which includes data about the crown and root location in the implantation site, is directly

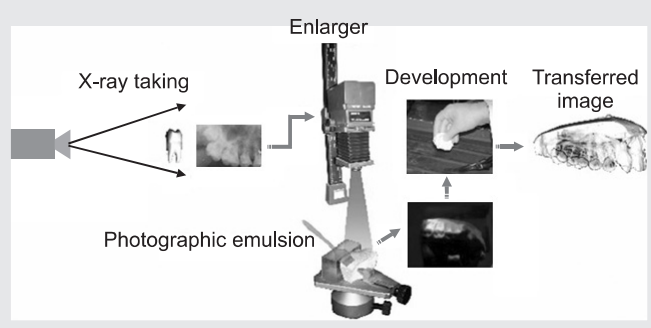

Figure 1. Schematic illustration of principle of film image transfer system (FITS).

Taek-Su Go, et al: Film Image Transfer System (FITS): An Efficient Method for Proper Positioning of Orthodontic Mini-implants. J Kor Dent Sci 2011. super-imposed on the plaster cast model, the surgical guide can be easily and accurately fabricated. We have developed the Film Image Transfer System (FITS) which provided more direct and accurate information on the dental cast prior to fabrication of the surgical guide ${ }^{13)}$.

This clinical report describes the newly developed FITS for proper positioning of the mini-implant in the narrow interdental space and considerations for better application.

\section{Materials and Methods}

\section{Film Image Transfer System (FITS)}

The principle of FITS is based on art techniques of Hyperrealism in painting ${ }^{14)}$. Several techniques of Hyperrealism were applied to allow accurate transfer of images. One of the techniques is to use a film projector to project an image on to a canvas, and then to trace the image on the canvas. The FITS reported herein uses x-ray film instead of picture film and a working model instead of a canvas.

The FIT System includes four main components: 1) Dental radiographic film, 2) Photographic emulsion coated model, 3) Transfer light - film projector, and 4) Processing and protection. A schematic illustration of the principle of FITS is shown in Fig. 1. Using FITS, the image of the film reverses the color. Therefore, black becomes white and white turns black (Fig. 2).

\section{FITS and Surgical guide fabrication procedure for orthodontic mini-implant}

$1.8 \mathrm{~mm}$-diameter and $8.5 \mathrm{~mm}$-long sand blasted with large grit and acid etched mini-implants (C-implant, Cimplant Co, Seoul, Korea) were used as hooks for intermaxillary elastics in a 16 year old female patient with anterior crowding. The implantation sites planned for mini-implants

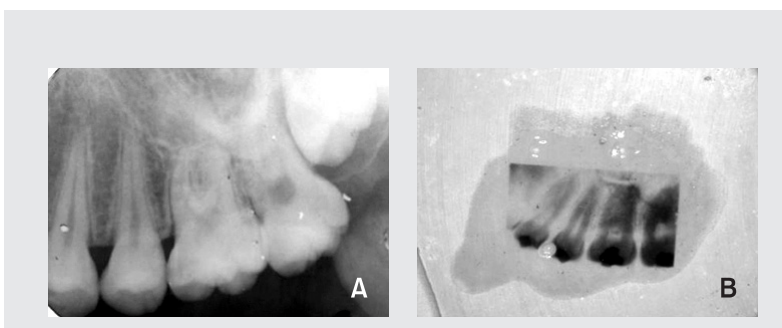

Figure 2. (A) Periapical radiographic view and (B) Constructed FITS image.

Taek-Su Go, et al: Film Image Transfer System (FITS): An Efficient Method for Proper Positioning of Orthodontic Mini-implants. J Kor Dent Sci 2011. 

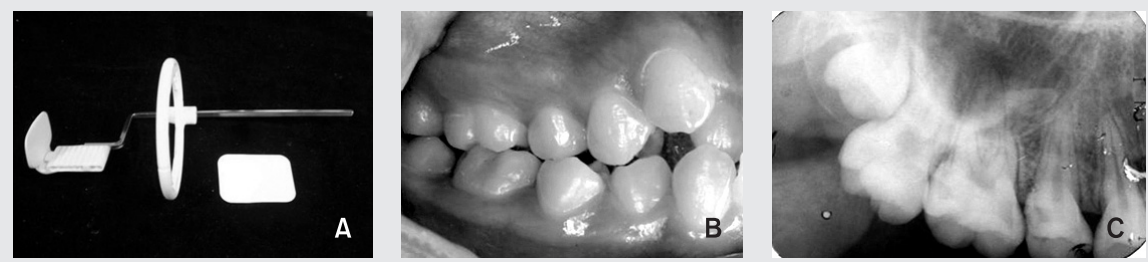

Figure 3. (A) XCP film holder for parallel x-ray taking, (B) Right side of intraoral photograph, (C) Periapical view.

Taek-Su et al: Film Image Transfer System (FITS): An Efficient Method for Proper Positioning of Orthodontic Mini-implants. J Kor Dent Sci 2011.
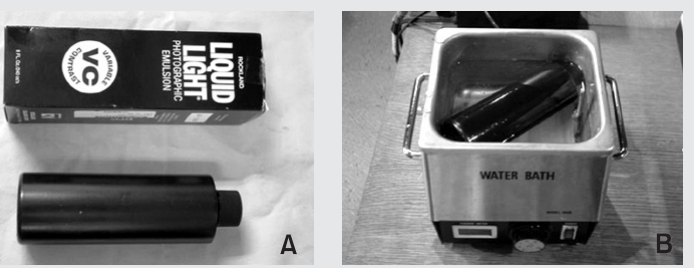

Figure 4. (A) Photographic emulsion, (B) Water bath (The water temperature in the bath should be maintained at $40^{\circ} \mathrm{C}$ ).

Taek-Su Go, et al: Film Image Transfer System (FITS): An Efficient Method for Proper Positioning of Orthodontic Mini-implants. J Kor Dent Sci 2011

were in the dentoalveolar bone between the upper second premolar and first molar.

\section{Result}

\section{Dental radiographic film and bite record}

Intraoral standard film must include the image of the whole crown and roots of the adjacent teeth. And it must be matched with the crown of the model. A parallel x-ray exposure method with the XCP film holder (Rinn Corporation, Illinois, USA) was used (Fig. 3). While taking the image, the film should not be bent. This can result in image distortion and positioning errors

\section{Photographic emulsion coated model}

Photographic emulsion is photo-sensitive. Artists and painters use this material for their works. The authors used the silver halide emulsion products (Liquid light photographic emulsion, Rockland colloid Co, NY, USA) (Fig. 4A). The model was fixed on the table and before use the bottle of emulsion was cooled in a $40^{\circ} \mathrm{C}$ water bath (Fig. 4B). The photographic emulsion was coated on the model in the darkroom, and then placed in a paper box which was pain-

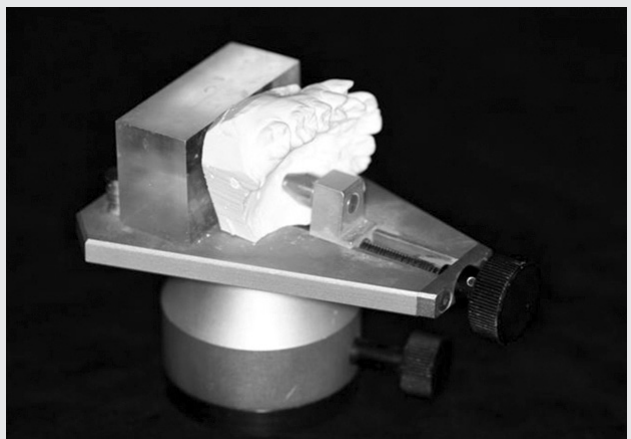

Figure 5. Vertical positioning appliance for FITS model.

Taek-Su Go, et al: Film Image Transfer System (FITS): An Efficient Method for Proper Positioning of Orthodontic Mini-implants. J Kor Dent Sci 2011.

ted black and lightproof. The model was dried for about one hour in the box. Drying with hot air should be avoided to prevent burning out the image.

\section{Transfer film image on the model using transfer light - film projector (enlarger)}

All procedures must be performed in the darkroom. The coated model was placed on the vertical positioning appliance (Fig. 5). Install the dental radiographic film in the projector. The light which is projected should be perpendicular to the ground. This can be achieved by using the level tester that is attached to the projector (Fig. 6). The focus distance of the film projector was too long to project onto the model. Therefore, we used a photo enlarger, such as units used to project film on photo paper in photographic printing. The projector/enlarger was equipped with a safe light so the x-ray image could be projected on the model without activating the photo emulsion. The x-ray image of the crowns was matched to the dental crowns on the model 
(Fig. 7A). Once the x-ray image was accurately superimposed on the model, the safety filter was removed to expose the photographic-emulsion coated model for about 6 seconds using an automatic timer (Fig. 7B).

\section{Processing and protection}

After exposing the photo emulsion coating on the model, the image was developed with a working solution for a paper developer (Dectol, Eastman Kodak Co, Rochester,
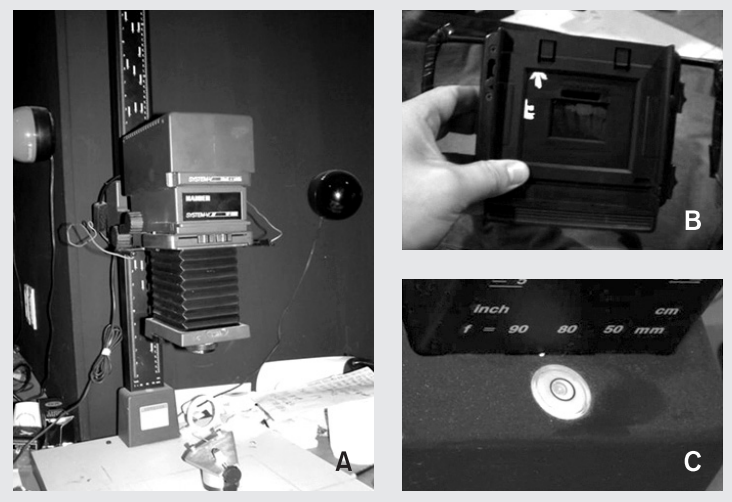

Figure 6. Transfer light - film projector and film adapter (A, B), (C) Projector should be positioned perpendicular to the ground.

Taek-Su Go, et al: Film Image Transfer System (FITS): An Efficient Method for Proper Positioning of Orthodontic Mini-implants. J Kor Dent Sci 2011
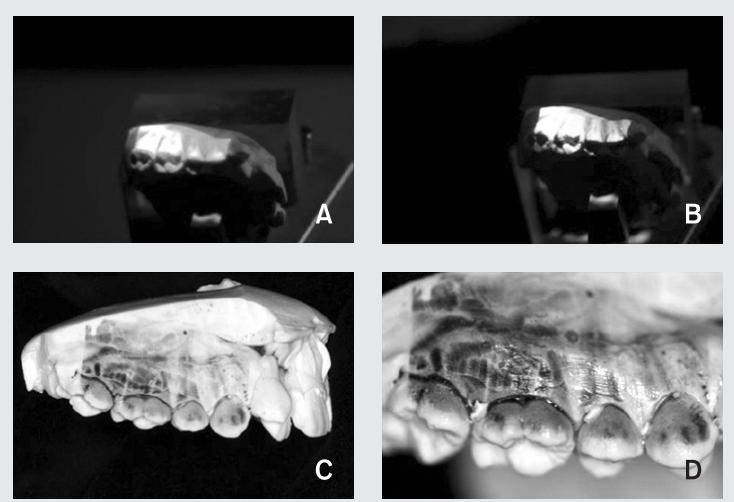

Figure 7. FITS procedure (A) Expose the safe light on the photographic-emulsion coated model until the crown of the model is matched to the projected image, (B) Project the image light on the model about 6 seconds using an automatic timer without a safe filter, (C) Image transferred model, (D) Marking for mini-implant placement.

Taek-Su Go, et al: Film Image Transfer System (FITS): An Efficient Method for Proper Positioning of Orthodontic Mini-implants. J Kor Dent Sci 2011.
NY, USA) diluting 1 part developer to 2 parts water and using a non-rapid hardening fixer (GBX fixer, Eastman Kodak Co, Rochester, NY, USA). The image was washed in cool running water. To protect the transferred image, stone hardener was applied on the model after it was dried. The $\mathrm{x}$-ray film image was successfully transferred to the dental cast (Fig. 7C) and the implantation position was marked with a pen (Fig. 7D).

\section{Surgical guide fabrication procedure (Fig. 8)}

The model which was placed on the vertical positioning appliance (Fig. 5) was located on the table of the milling machine which was checked by a level tester (Fig. 8A). The drill of the milling machine was collimated on the image of the space between the roots which had been transferred by FITS. And then the guide hole from the prefabricated resin block was fabricated using the milling machine.

\section{Intraoral application of surgical guide and im- plantation procedure (Figs. 9-11)}

The mini-implant was placed using this custom-made surgical guide as described in a previous article ${ }^{14)}$ and a post implantation periapical radiographic view showed a successful implantation result. Class III intermaxillary elastics were applied to the hook of the C-implant during orthodontic treatment (Fig. 12).
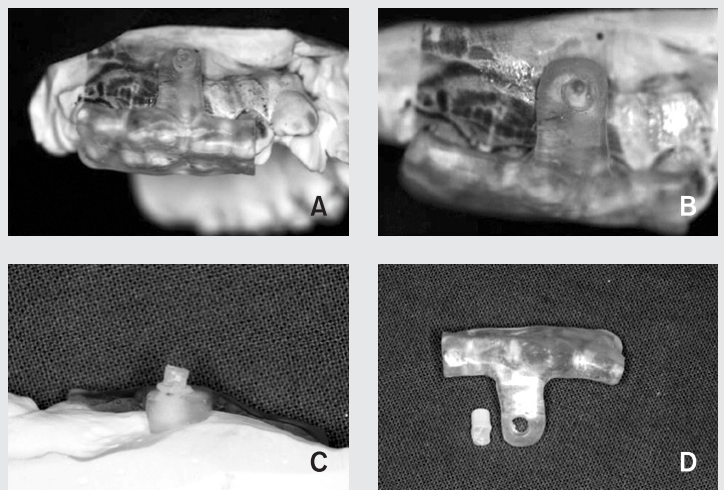

Figure 8. Surgical guide for $\mathrm{C}$-implant (A) Hole for guide drilling is made to the prefabricated template on the FITS model using milling machine, $(B, C)$ Hole for miniimplant placement and guide drilling, (D) Composed of two separated parts.

Taek-Su Go, et al: Film Image Transfer System (FITS): An Efficient Method for Proper Positioning of Orthodontic Mini-implants. J Kor Dent Sci 2011. 

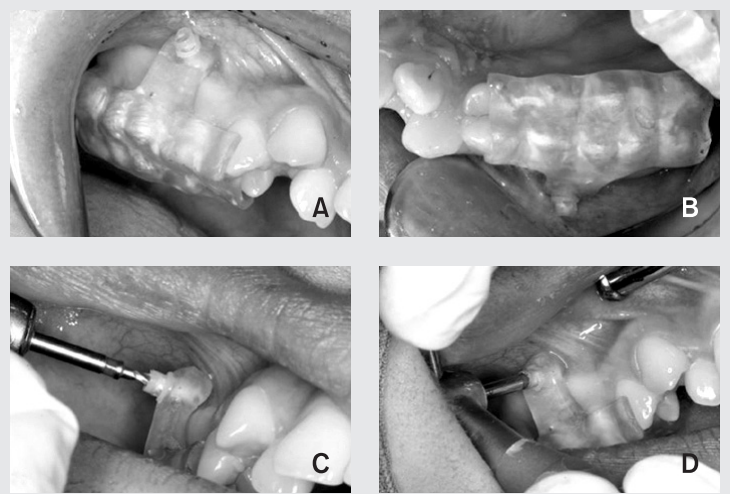

Figure 9. Intraoral application of surgical guide and pilot drilling procedure. $1.5 \mathrm{~mm}$ in diameter guide drill is used for $1.8 \mathrm{~mm}$ in diameter mini-implant.

Taek-Su Go, et al: Film Image Transfer System (FITS): An Efficient Method for Proper Positioning of Orthodontic Mini-implants. J Kor Dent Sci 2011.
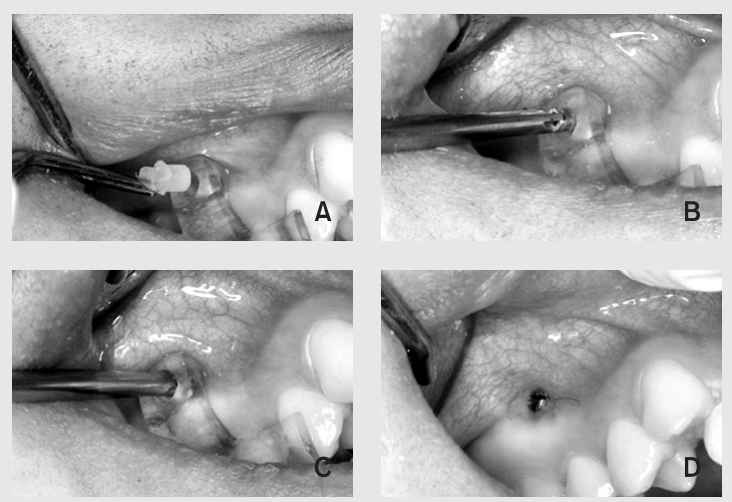

Figure 10. Convertible cap for guide drilling was removed and screw part of C-implant was delivered through the surgical guide hole.

Taek-Su Go, et al: Film Image Transfer System (FITS): An Efficient Method for Proper Positioning of Orthodontic Mini-implants. J Kor Dent Sci 2011.

\section{Discussion}

As the usage of the orthodontic mini-implant increases, clinicians have realized the challenge of proper positioning of the mini-implant ${ }^{4,14-18)}$. FITS has an advantage in that all procedures can be performed in the laboratory using only a cast model and one precisely taken $\mathrm{x}$-ray film rather than a $\mathrm{CT}$, several periapical views, or a complicated guide system. Even though this method is less accurate than cone beam CT based surgical guide systems, it enables the cli-
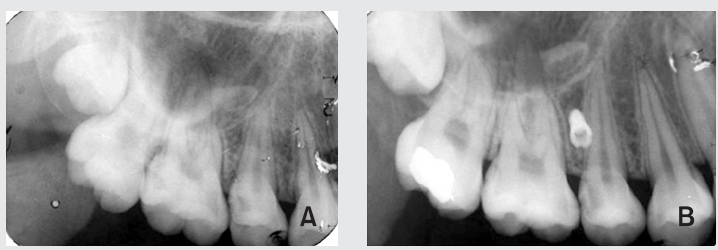

Figure 11. Pre and post implantation periapical radiographs. Mini-implant is well positioned as planned to the FITS model.

Taek-Su Go, et al: Film Image Transfer System (FITS): An Efficient Method for Prope Positioning of Orthodontic Mini-implants. J Kor Dent Sci 2011.
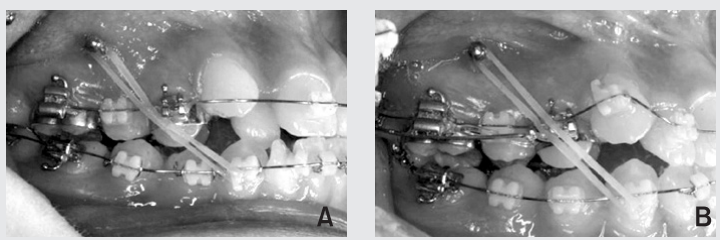

Figure 12. (A) Initial loading on the C-implant 4 weeks after placement, (B) 3 months after initial loading. Application of intermaxillary elastics during orthodontic treatment.

Taek-Su Go, et al: Film Image Transfer System (FITS): An Efficient Method for Proper Positioning of Orthodontic Mini-implants. J Kor Dent Sci 2011.

nician to minimize risks while installing the mini-implant ${ }^{12,14)}$. The pre-made surgical guide offers reproducible location of the site and vector of placement of the miniimplant.

However, there are a few drawbacks. Firstly, technical skill is required to take a periapical image. But this procedure can be performed by a skillful technician under the instruction of the clinician. To compensate for this disadvantage, an XCP film positioning appliance (Fig. 3) can be used. Currently, we use a paralleling technique using the appliance with bite wax. The bite part of the XCP should have the bite record which locates the image to the model. It organizes the image and the model just like 3-dimensional intraoral location of the film. Bite recording material should not have radiopacity which will block important parts of the image. Secondly, a dark room and supplies for developing the film are necessary.

Thirdly, image distortion of the projected x-ray can occur when there is severe alveolar wall curvature over the roots in the proposed implant site. Typically, the anatomical area between the upper second premolar and first molar is 
relatively flat so there is no clinical disadvantage for using FITS.

Severe curvature of the model will blur the image by creating a difference of focal length. If the curvature in the interdental alveolar bone between the second premolar and the first molar is severe, the implantation area of the cast can be trimmed to a flat surface to eliminate distortion. In this case you will need to fabricate the guide with some space between the interior surface of the guide and the trimmed area of the model. This will avoid tissue impingement when the surgical guide is fitted to the crowns of the teeth.

The more accurate the surgical template, the more favorable the mini-implant position. In order to make a more precise surgical template, direct and accurate information about the roots must be provided for the model at the same time and location. Anatomical structures such as the sinus can be taken into account in FITS. FITS is also very effective for the application of the surgical template for a single or a couple of prosthetic implants as well as orthodontic miniimplants in the adjacent dilacerated roots or extended sinus cases.

\section{Conclusion}

The use of mini-implant anchorage is growing rapidly, but is still in the development stage. Reports indicate a failure rate in mini-implant placement that is higher than is comfortable. However, the benefits for the patient of a wellmanaged case using 100\% anchorage encourage orthodontists to employ the technology, and to strive to minimize failures. The FITS technique represents an effort to minimize risk to the patient and produce consistently good results based upon accurate information about the anatomy of the implant site.

\section{References}

1. Akça K, Iplikçioğlu H, Cehreli MC. A surgical guide for accurate mesiodistal paralleling of implants in the posterior edentulous mandible. J Prosthet Dent. 2002; 87: 233-5.

2. Verde MA, Morgano SM. A dual-purpose stent for the implantsupported prosthesis. J Prosthet Dent. 1993; 69: 276-80.

3. Takeshita F, Suetsugu T. Accurate presurgical determination for implant placement by using computerized tomography scan. J Prosthet Dent. 1996; 76: 590-1

4. Kyung HM, Park HS, Bae SM, Sung JH, Kim IB. Development of orthodontic micro-implants for intraoral anchorage. J Clin Orthod. 2003; 37: 321-8

5. Carano A, Velo S, Incorvati I, Poggio P. Clinical application of the miniscrew-anchorage-system (M.A.S.) in the maxillary alveolar bone. Prog Orthod. 2004; 5: 212-35.

6. Maino BG, Maino G, Mura P. Spider screw: skeletal anchorage system. Prog Orthod. 2005; 6: 70-81.

7. Carano A, Melsen B. Implants in orthodontics: interview. Prog Orthod. 2005; 6: 62-9.

8. Chung KR, Kim SH, Kook YA. The C-orthodontic micro-implant. J Clin Orthod. 2004; 38: 478-86.

9. Morea C, Dominguez GC, Wuo Ado V, Tortamano A. Surgical guide for optimal positioning of mini-implants. J Clin Orthod. 2005; 39: 31721.

10. Suzuki EY, Buranastidporn B. An adjustable surgical guide for miniscrew placement. J Clin Orthod. 2005; 39: 588-90.

11. Choi HJ, Kim TW, Kim HW. A precise wire guide for positioning interradicular miniscrews. J Clin Orthod. 2007; 41: 258-61

12. Estelita Cavalcante Barros S, Janson G, Chiqueto K, de Freitas MR, Henriques JF, Pinzan A. A Three-dimensional radiographic-surgical guide for mini-implant placement. J Clin Orthod. 2006; 40: 548-54

13. Chung KR, Kim SH, Kook YA. C-orthodontic mini-implant. In: Cope JB, ed. OrthoTADs book: clinical guideline and atlas. Ventura: Underdog media; 2007: 248.

14. Meisel LK. Photorealism. 1st ed. New York: HN Abrams Inc.; 1980.

15. Kim SH, Choi YS, Hwang EH, Chung KR, Kook YA, Nelson G. Surgical positioning of orthodontic mini-implants with guides fabricated on models replicated with cone-beam computed tomography. Am J Orthod Dentofacial Orthop. 2007; 131: s82-9.

16. Maino BG, Bender J, Pagin P, Mura P. The spider screw for skeletal anchorage. J Clin Orthod. 2003; 37: 90-7.

17. Carano A, Velo S, Leone P, Siciliani G. Clinical applications of the miniscrew anchorage system, J Clin Orthod. 2005; 39: 9-24.

18. Bae SM, Park HS, Kyung HM, Kwon OW, Sung JH. Clinical application of micro-implant anchorage. J Clin Orthod. 2002; 36: 298302. 